\title{
Spatial movement as a resistance strategy in a holocaust novel $A$ Blessing on the Moon
}

\author{
Sri Sumaryani \\ Office of International Affairs and Partnerships, \\ Universitas Negeri Yogyakarta, Indonesia \\ Correspondence: \\ Email: srisumaryani@gmail.com \\ Revised: \\ 12 January 2021 \\ Accepted: \\ 27 February 2021 \\ Published: \\ 28 February 2021
}

Received:

22 August 2020

\begin{abstract}
Exploring Jewish resistance in relation to the Holocaust has become one major topic widely discussed in the Holocaust novels written by the second or third generations of Holocaust survivors. The fact that these writers primarily have no direct experience with the event somewhat shows that the paramount effects of the tragedy expand generations and leave trauma that lingers. To cope with the narration of atrocities, resistance strategy is often employed by the Holocaust writers and to a certain point has a function to represent the struggle of the survivors. Joseph Skibell as the thirdgeneration writer deploys a strategy of spatial movement as a coping mechanism and resistance against atrocities in his magical realist novel $A$ Blessing on the Moon. Using Sara Upstone's spatial politics perspective, this research aims to investigate the spatial movement performed by the main character and to explain how it produces the resistance strategy. In doing so, it will also further examine the scale and characteristics of various spatial locations used in the novel as a means of resistance. As it goes along, the issue of trauma and identity of the Holocaust survivors and their descendants is also explained.
\end{abstract}

Keywords: resistance; Holocaust; spatial politics; magic realism

\section{INTRODUCTION}

With the span of merely 4 years, approximately 6 million European Jews were murdered during the Shoah (Harvey, 2002), caused the shrunk of the European Jews population, and left the rest to flee the Europe. Some of the survivors came to the United States, continued to live and have made into their second and third generations. Some of the second and third generation descendants mark their way as the Holocaust writers, attempting to channel the trauma of the memory which they have not experienced per se. There is a significant difference on how the older and younger generations of Holocaust writers narrate their memory on the tragedy. Joseph Skibell as a representation of the third generation departs from historical realism, a genre generally employed by mainly older authors, to narrate the tragedy. 
Sumaryani, S. (2021). Spatial movement as a resistance strategy in a holocaust novel A Blessing on the Moon. EduLite: Journal of English Education, Literature, and Culture, 6 (1), 165-178.

http://dx.doi.org/10.30659/e.6.1.165-178

By employing magic realism, he recounts the story of his deceased great grandfather, Chaim Skibelski, who was killed during the Holocaust in his novel A Blessing on the Moon. The story revolves around the protagonist Chaim who revives from death and attempts to find the location of The World to Come. By invoking the discourses of life and death, Skibell attempts to resolve the past (Dean, 2012) by reconstructing the Holocaust based on his memory. The discussion of the memory of the Holocaust for the third generation like Skibell is problematic for he hardly has any actual accounts of the tragedy. On being asked about the memory, Joseph Skibell responds by saying, "The silence, I think, haunted me as a child and formed my character in a number of ways. ... So the book is an attempt on my part to recover from the silence, a family history that, except for a clutch of photos and whatever is encoded genetically, had all but disappeared" (Grimwood, 2007, p. 83). The denial mechanism through silence is normally used by the survivors to protect themselves from future dissatisfaction and pain in close relationships (Barel et al., 2010). What they have not realized is how the silence has created trauma for the descendants. They struggle to understand the meaning of a tragedy that has historically shaped their identity as Americans with immigrant background but at the same time are being forbidden to talk about it.

Skibell attempts to build a connection between his identity as a descendant of the survivor and as an American by constructing narration about journey through spatial movement. The choice of journey is not alien to writers who employ the magical realist style. One of the distinct features of magical realist text is indeterminate space and time (Faris, 2004). Chaim's journey corroborates the feature as it has no clear site of departure and arrival. Moreover, the journey also symbolizes Skibell's trajectory to understand his past. The narration of the protagonist Chaim going to several locations in order to find the World to Come can be read as a representation of his family's migration to find a safe land in order to continue life and at the same time as his continual struggle to deal with trauma.

However, by employing magic realism to narrate historical event like the Holocaust, the issue of inauthenticity as a critical response often emerges. The current generations of authors are liable to being accused of not staying true to the tragedy and labelled as antirealistic. It eventually makes some of them avoid direct representations of the Holocaust and thematically turn to the hardship as the result of trauma (Kolárir, 2019). Skibell's portrayal of his protagonist focuses more on his struggle rather than the depiction of the event's brutality. Skibell's manifestation of the tragedy may be labelled as inauthentic yet it rings true to his traumatic experience resulted from the silence. His narrative is an attempt to put meanings to the silence he experienced or quoting Kolár (2017) to fill in "the gaps in offspring's knowledge of their grand/parents' history".

Skibell is also constantly building the sense of the loss of time and space in the narrative only to later bring them back again. This technique is done many times so there is a blurred boundary between the real and the magical, the physical and the abstract, place and space. The blurred line serves as one of the distinct features of magical realist fiction. It is used to depict the unexplainable pain that has to be endured by the victims, survivors, and descendants. As a modern Jewish-American author, Skibell also uses this 
technique to describe his difficulty to understand his past and how he shall place himself as a part of the tragedy.

I argue that this is the case faced by most Jewish-American authors who want to embrace and understand their past and at the same time establish themselves as authors with distinct American identity, which differentiate them from the other authors with the same domain but different nationality. Saperstein (1984) mentions that the choice by Jewish-American writers to continually use their Jewishness as a significant aspect of their narration shows the encounter between America and the self. It shows how the narration is relevant with their Jewish and American identity, his status as a modern writer, and his contemporary readers. From this, we may see why issues of identity and trauma serve as pivotal backgrounds for Skibell to build his narrative that centers on movement.

In regards to the movement in the form of journey by the protagonist Chaim, the underlying motive is clearly survival. Without survival, he will not be able to reach the World to Come. Here, the World to Come becomes the less pivotal motive because what Chaim fights for and experiences many times in the narrative is the need to survive. "Survival as a form of resistance is a common theme in most post-Holocaust narratives" (Arva, 2008, p. 85). What is being resisted in the case of Chaim is mostly not clearly presented. It is located invisibly within the structure of various spatial locations. The spatial setting of places he visits is functioned as the embodiment of more powerful force that threatens his safety and furthermore pushes him to move. The displacement nonetheless shows how Chaim's steadfast insistence to always move rather than yield and accede his freedom to the force of the more powerful is what is seen as a form of resistance.

This paper is written to examine various spatial settings depicted in the novel to which the protagonist responds by performing resistance. From his former house to the lap of his mother, each setting has spatial characteristics that will further be explained using Sara Upstone's assumptions on spatial politics. By doing so, it also attempts to explain issues of trauma and identity experienced by the Holocaust survivors and their descendants.

On the discussion of power and space, Upstone (2009) contends that space has an important part in playing out resistance. The differentiation between the terms space and place is significant to begin with to explain how power plays its part which furthermore will always attract resistance. Open space with its chaotic reality and characteristics always attract any power to discipline it by establishing order and border. Chaos in space is initially perceived as a neutral factor which later being utilized by the colonial to construct a system and obscure fluidity that relies within, thus creating what is called as place. Place is a controlled spatial location imbued with political interests, that most likely will appear with a single and fixed identity to obscure the diversity.

However, place never completely gets rid of the diversity within it. When the colonial power attempts to erase it and to continually write and overwrite it with new interpretation and claim it as original, the attempt always leaves traces. The traces appear, according to Derrida, as a consequence of the writing and overwriting process yet in the first place, there is never an origin, only traces being obscured (Derrida, 1997). These traces reveal the instability 
Sumaryani, S. (2021). Spatial movement as a resistance strategy in a holocaust novel A Blessing on the Moon. EduLite: Journal of English Education, Literature, and Culture, 6 (1), 165-178.

http://dx.doi.org/10.30659/e.6.1.165-178

and inability of the colonial power to completely subvert the fluid space. And thus, it becomes the point of departure to build resistance.

In the spatial context, this resistance can be manifested through various spatial locations hidden within a fixed-scale space claimed by a colonial power. Nation, for instance, is a possible spatial location to build resistance, yet it is often seen as a product of the same colonial or neo colonial system (Upstone, 2009). Upstone later offers several possible locations to consider, namely journey, city, home, and body. Each scale offers a particular characteristic which makes resistance possible. Through these scales, transgression to the colonial boundaries and orders is performed. She later meticulously explains several possible "styles" of resistance employed by postcolonial authors within the framework of those four scaled-locations.

Upstone's theoretical assumptions are closely linked to postcolonial issue which underscores the discussion of power relation. It may create an impression that the theory is solely applicable only for postcolonial cases which explicitly engage with the power relation between the colonial and colonized. However, noting that the spatial assumptions are also built under the light of Foucauldian perspective, this theory is also applicable for any power establishment on behalf of a particular group whose interest is to dominate. Foucault (1990) argues that resistance will always emerge whenever there is power. The possibility of resistance emerging from any power exertion is discussed in several researches that examine power relation by means of geographical boundaries.

Investigating apartheid South Africa through Nadine Gordimer's two novels, Shabanirad \& Dadkhah (2017) find that the geographical boundaries create South Africa as a spatial entity that represents colonial dominating power. The spatial boundaries eventually draw resistance from the urban South African society affected by the apartheid policy. Referring to Foucault that mentions this resistance site as heterotopias - the resistance is built from the individual bodies which later develop into social movement - here, the micropolitics of the body is manifested through urbanization that has potency to perform transgression.

Both solid and magical bodies are represented in the postcolonial narratives and show a particular emphasize on how body and place are interconnected. Upstone (2009) shows this interconnectedness through a term widely used by feminist scholars named chora. While most feminist critics tend to criticize it for its specific gendered function as a means to build negative construction towards women that enforce subordination by referring it as merely a part of bodily construct, quoting Sallis who explains Plato's origin term chora, Upstone contends that chora must be seen in a more general spectrum, a body without gendered connotations. It exists before any fixed meanings emerge. It is no wonder that when the appropriation of place by colonial starts, it begins from the bodily-scale site. The difference of color pigment, for instance, becomes the justification for institutional racism and colonization. Thus body becomes the possible and potential site of resistance. Considering types of resistance built through a minuscule scale in the light of Foucauldian perspective, Tyler (2004) also finds that resistance in George Orwell's 1984 is ranging from a room, facial expression and bodily gesture, to 
diary-scale site. The minuscule scale resistance depicts individual movement to transgress the disciplined space by deploying local objects close-by.

Regarding spatial movement, journey is a scale that needs to be considered as well. To response colonial's interest for an absolute spatial subjugation, movement through migration generally becomes a choice for the colonized. The transfer of body utilizes chaos (Upstone, 2009) within place to break through the confines of the colonial and at the same time to violate order imposed by the colonial. By doing that, resistance is performed. However, this breaking through eventually will bring the individual to other possible locations that have been appropriated by the colonial, thus bringing the colonized into a hopeless and problematic journey because there is no final arrival or departure (Upstone, 2009). But what is most pivotal to underline in journey is the fluid and discontinuous quality which provides mutable quality (Uptone, 2009).

On the discussion of Joseph Skibell's A Blessing on the Moon through several researches that have been conducted, there is still lack of critical discussion that centers on spatial movement as a means of resistance. Most researches on the novel mainly engage with the magical realist genre as an effective way to channel trauma, history, and memory of the Holocaust. This analysis is meant to close the gap on the missing discussion on resistance through spatial movement and to offer possible manner in understanding the tragedy.

\section{METHOD}

This research uses descriptive qualitative method. The researcher performs a close reading technique on literary texts. On the reading process, literary data that contain the description of spatial locations and spatial movement are gathered and then are analyzed critically based on the assumptions of spatial politics theory proposed by Sara Upstone. The analysis of the characteristics is used to reveal to what extent spatial movement performs its part as a resistance strategy for the main character which further also explains how discussion of spatial locations and movement are crucial for issues related to the issues of trauma and identity for the Holocaust survivors and their descendants.

\section{RESULTS AND DISCUSSION}

As the third generation of the Holocaust survivors, Joseph Skibell has never experienced the telling of the tragedy from his families. Like what commonly happens among the families of Holocaust survivors, silence often marks the intergenerational relationship. The absence of the talk on the event eventually leaves a different kind of trauma to the descendants. Skibell's attempt to fill in the "void" resulted from the silence is by creating imagination on the tragedy. He reconstructs a story beyond his memory and determines his stance on the tragedy by choosing a magical realist narrative in the form of journey.

I argue that the geographical migration in the narrative is a metaphor for Skibell's own trajectory to understand the difficult journey of his family. His protagonist, Chaim Skibelski, who is named after his great grandfather who died during the Shoah, corroborates the argument. Along the journey, Chaim 
Sumaryani, S. (2021). Spatial movement as a resistance strategy in a holocaust novel A Blessing on the Moon. EduLite: Journal of English Education, Literature, and Culture, 6 (1), 165-178.

http://dx.doi.org/10.30659/e.6.1.165-178

visits several locations which interestingly are different from one another in terms of structure and scale. The movement is propelled by certain power whose influence is manifested through the outer and inner characteristics of the locations. The power clearly functions as an allegory for the Nazi's gripping existence which haunts Chaim and makes him always in constant moves. From Skibell's perspective, the unseen power is the manifestation of the silence that has created trauma and that he wants to fight back. Instead of perceiving the displacement as a form of surrender, this section offers to see the act as a form of resistance by scrutinizing the protagonist's response to the spatial locations that hampers him from finding the World to Come. In total, there are ten spatial locations worth mentioning in accordance to the main character's resistance. From a burial pit to the moon's surface, each location owns particular characteristics that generally prevent him to stay and force him to do constant roaming in the living world. This section will offer analysis to some of the locations.

The story opens up with Chaim reviving from death with hideous appearance as a result from the Einsatzgruppen's shots. The first place that Chaim visits straight from his rise from death is his former house that now has been occupied by a Polish family, the Serafinskis, who cannot sense his presence. Chaim's decision to come to his house is understandable since his home functions as a symbol which connects him with the world of the living. In the sequence of home narrative, Chaim is still unsure about the world he belongs. He is torn apart between the search for the World to Come and the urge to cling to the living world. Thus, when he witnesses what the Serafinskis have done to his belongings, he rebels straightaway against them. He scares away them yet only one of them realizes his presence, the Serafinski's daughter, Ola.

Chaim begins to use the house's furniture to scare away the Serafinskis. By creating chaos within the family order, Chaim hopes that they will all leave the house. He deliberately smears his blood dripping from his decaying body "in the hallway, through the rooms, on the staircases ... on the patterned wallpaper, at every level, so that they cannot be missed". The smearing of blood on the household furniture has tainted the order created by the current owner. This is an act of transgression aimed to penetrate the new order. Prior to Chaim's coming, the new order has been implemented in the house along with the coming of the new occupants. The house as space should never be deemed as a neutral emptiness, but a web of social, cultural, and ideological relations which conditions its inhabitants (Romero \& Rodríguez, 2006). The inhabitants can utilize it according to their interests, including establishing a new structure to overwrite the old. As a space that has been turned into place to accommodate the need of the new inhabitants, the house recreates new boundaries and characteristics that Chaim is unfamiliar with. To rebel against and wreck the new order, Chaim performs s strategy of resistance within the house structure by tainting it.

There are two power being contested here, the Polish family's and Chaim's. Chaim is successful in creating chaos through his liminal resistance since the whole family is made shocked by the daughter's constant screaming after witnessing the blood. However, the family's refusal to believe her statement creates another boundary that separates the family and her. She is 
later locked in her bedroom. This boundary leaves Chaim's liminal resistance in vain since his influence now can only be felt within the bedroom space where the girl is being locked and leaves the rest of the house back in its order. When the daughter later dies, so does the trace of his resistance. To no surprise, Chaim's resistance is then overpowered by the family.

However, it is inevitable for the "traces" of the past to fully disappear for they are intertwined with the present and future (Derrida, 1997, p.61). When new order is layered on the old one, the later never really disappears. The house that has been turned into place through appropriation still keeps the traces of the past. The traces keep appearing and rejecting the overwriting process that continually is performed by the dominant power to erase their existence. Through these remnants, a new step of resistance is always possible to build because these traces contain identity that previously contributes to shape its former inhabitants. They are impossible to erase. Through this distinct identity that formerly has been tried to be erased by the current hegemonic power, Chaim finds a new strategy to resist. When Chaim discovers "the pictures of my daughters .... hidden away in a locker filled with old rags and oily motor parts" (Skibell, 2010, p. 51), he knows that he can break the house's new structure from within because there is always a gap to reveal the true face of the illegitimate power that now has control over it. The pictures will be used as a means to prove that he is the legitimate owner of the house.

Chaim's hope to regain total control over the house is shattered when the Seranfinskis realize his presence. They cannot sense him, yet they understand his motive when Chaim starts to tease and disturbs their lives. As a response, they throw rampant anti-Semitic curses towards him. Chaim realizes that his Jewish identity will never leave him undisturbed even though he already dies. It is the same identity that puts him to death. Whenever he uses his identity to reaffirm his being, it will on the contrary always fling him back to the very reason that tries to erase his being. The traces which are about to be used to help him build the resistance within the house in the end provides all possible reasons for him to leave the house.

Home as a domestic space according to Upstone (2009) has its own identity that always questions classifications imposed within. This serves as a significant factor to start resistance against the hegemony. When Chaim is about to utilize it to interrogate the hegemony, it backfires on him. For Chaim, the identity that gives distinguishing label on him when he is still alive is the same labelling that he wants to get rid of off his being completely when he is revived. Here, the identity that is tried to be revealed by the house structure is exactly the identity that is formerly used to annihilate him. At the end of the house narrative, Chaim realizes that he is dead and the place that he is looking for should be the World to Come, not some spatial location connected to the living world. Thus he leaves the house in the spirit of finding the World to Come. This act should be seen as a resistance strategy for he chooses not to surrender to the hegemony within the house but decides to follow his purpose, this time with a firm belief on his position as a wandering soul that needs a place to rest.

The atrocity of the Holocaust has ended his life inhumanely and thus his soul is traumatized. He hardly finds peace in death, thus his soul does not rest in the World to Come. The World to Come or what has been mentioned in 
Sumaryani, S. (2021). Spatial movement as a resistance strategy in a holocaust novel A Blessing on the Moon. EduLite: Journal of English Education, Literature, and Culture, 6 (1), 165-178.

http://dx.doi.org/10.30659/e.6.1.165-178

the Jewish scripture and teaching as Olam Haba is the place for eternal state of rest and delight for souls where they can unite with the Divine while Olam Hazeh is the place for testing and earning in the living world (Mishor, 2016). They are two essential concepts in Jewish theology. The fact that he does not end up in place according to his belief perturbs him. Due to brutality he experienced, the search for Olam Haba is aimed not only to rest his soul properly according to his religious belief but also to erase the trauma caused by the tragedy.

The searching for the World to Come depicts the trauma issue faced by the survivors of the Holocaust and their descendants. There is no possible way that will be able to completely erase and separate them from the tragedy. The identity of the Jewish people includes the long history of persecution and injustice that propel them to perform migration. Therefore, constant movement from one place to another is closely related to the Jewish people's struggle to liberate them from political and religious hegemony. From historical point of view, rather than seeing this as a form of defeat, it should be discerned as a form of bravery to continue life. Skibell's narrative when portraying Chaim's constant movement and displacement from one place to another when looking for the final resting place is deemed comparable with the modern Jewish's struggle to deal with the trauma. Finding the liberating space from the redemptive perspective is only possible to achieve if there is no more memory that reminds them of the tragedy. However, the memory of the Holocaust will always have interconnectedness with the Jewish identity as long as they live. It is as if to gain complete liberation means to deny their own existence. This is not possible in the living world. Therefore, Skibell offers us to visit abstract spatial locations in his narrative by utilizing magical realist technique, to visit locations where the unimaginable becomes possible.

Having seen the house as a representation of spatial location with rigid order, the readers may have speculated that the World to Come is a place with no border or rigid structure. The following spatial locations that will be discussed suit the characteristics. However, in the end, they do not serve as the locations that liberate Chaim. For instance, a spatial location that is as open as a wheat field still holds physical quality that restrains the inhabitants to gain freedom. The "snow, three thousand bundles dropped by a careless traveler" (Skibell, 2010, p. 85) in the wheat field makes Chaim and his Jewish parties who are bound together looking for the World to Come chill due to the temperature drop. The "many thick quilts of snow" (Skibell, 2010, p. 74) in the burial pit also make the inhabitants shiver. It indicates how snow as a natural phenomenon from the living world is still able to put pressure on them. Snow is part of the cycle of seasons that classify weather into four categories. This fixed classification resembles order established by the hegemony. Moreover, Chaim's footsteps on snow are also used later by a dead Einsatzgruppen member who formerly shot him dead and now also revives from death to chase him. There is no safe space in the living world since there is always omnipresent power which performs surveillance over the inhabitants that roam in the physical world. Any place in the living world which holds rigid time division is unable to serve as a liberating choice for it contains orderly rules. This very reason becomes the sole reason for Chaim to do continual movements once he finds the hegemony which tries to penetrate and controls 
his own space. His movement among places depicts his rejection to surrender to the power that has taken control over these spatial locations

If spatial locations that initially seem spacious and open mentioned earlier turn into a dangerous place, so do locations with the smallest scale like a hollow tree. When he thrusts his body into the hollow tree, Chaim is performing transgression. Just when he thinks he can take some rest, a pack of wolves come and claim the territory that has been trespassed by Chaim. One of the beast's "green eyes glint in flashes as they sweep across thefield. Hunger, this curious word punds inside my brain. (Skibell, 2010, p. 89). This mode of surveillance is similar with Foucauld's panopticon, " $a$ segmented space, observed at every point, in which the individuals are inserted in a fixed place" (Foucault, 1979, p. 197). As a person whose movement is being monitored, he never realizes that he is under surveillance until he breaks the order being imposed by the omnipresent power. Chaim is not visible in the eyes of the wolves yet he was inside a tree which is surrounded by the surveillance system of the hegemony. Once he steps outside, he will be in danger. The surveillance system is operated through carnivores which commonly mark their territory by urinating on the tree. With their smell, they will sense if there is a foreign being that has broken into their marked territory. More importantly, the hollow tree is an object from the living world which has measurable size and structure. Any physical structure within the gaze has been the result of appropriation of the hegemonic power to build order. Surveillance is inserted to maintain the order in the form of patrolling wolves. It will directly fail Chaim as a safe spatial location and thus he rejects to become the object of surveillance and chooses to leave the site.

When Chaim and a group of Jewish people reviving from death finally arrive at Hotel Amfortas, they are deceived by the structure which leads them to perceive the place as the World to Come. Unlike previous spatial locations that have fixed scale and clear physical appearance, Hotel Amfortas has shown quality beyond the worldly measurement. It appears like heaven for the parties. Its magnificent visual shown through glittering façade with "thousands and thousands of windows ..... A river surrounds it on all sides..." (Skibell, 2010, p. 120) is able to lure Chaim and his group to enter it. The river that can wash away the decaying marks on their bodies is finally crossed by all of them. Chaim finds out later, after all of his parties perish, that the hotel is the replica of the concentration camp which exterminates its occupants. By looking closely to the structure of the building, windows and river surrounding the building function as borders that prevent the inhabitants from running off once they enter the hotel. In the narrative, the rigidity of structure always raises the alarm. Whenever there is order and border, it means that some unseen power is operating within.

Chaim finally decides to run off after realizing that all of his family members are exterminated in the hotel's steam bath, an analogy for the gas chamber in the concentration camp. Here, Chaim's movement to free himself from the confinement system once again should be clearly perceived not as an act of surrender but an effort to liberate himself from the persecution. The readers may also draw an analogy between this running off and the migration of millions of the European Jews after the Shoah to the United States and Israel. The desire to build a new life in a promising land gives the survivors 
Sumaryani, S. (2021). Spatial movement as a resistance strategy in a holocaust novel A Blessing on the Moon. EduLite: Journal of English Education, Literature, and Culture, 6 (1), 165-178.

http://dx.doi.org/10.30659/e.6.1.165-178

hope. Due to this migration, the number of the Jews in the Europe has dwindled significantly. The Europe from the spatial perspective is seen as place. The length of appropriation that has been done to turn its status from space to place is quite significant. Although it leaves rooms and traces for betterment, the damaging causes and effects that hurt the survivors' identity has been deeply rooted to the point when the discussion of their identity means reminiscence of the tragedy. Therefore, they chose to disengage from it.

However, it is impossible to get rid of the reminiscence of the tragedy completely. Being Jewish means always being connected with the Holocaust. To reject the connection means to completely get rid of their Jewishness which is impossible to do as long as they are still alive. The difficult struggle for the Jews to completely disengage from the memory of the Holocaust is portrayed in one section of the narration when Chaim is helping two Hasidic Jews to restore the moon to its rightful place. The moon's surface is portrayed as not clear but "have been mottled, as though with dark and purple bruises ... It must've drawn the blood into itself." (p. 243). The surface is also riddled with the bullet holes. The blood and the bullet holes that have tainted the moon is the blood of the Holocaust victims in the village that were shot dead by the Einsatzgruppen or Nazi death squad. The moon is already loaded with the dead bodies of the victims which leave marks on the surface. Thus, it fell from the sky and needs to be restored.

The falling moon is taken from the Jewish folklore telling a story of two Hasidic Jews that pull down the moon. The folklore as a representation of Jewishness is stained by the story of the Holocaust. Skibell shows how the event has a serious contributing factor to shape the identity of the modern Jews, which will always be connected with the discussion of the Holocaust. When Chaim is able to help them restore the moon to its rightful place, he is finally brought to the World to Come.

The World to Come appears as an abstract concept. Unlike the other physical locations which have been visited by Chaim, this world is located beyond imagination. The scale and borders is unknown and therefore it offers openness which will normally attract the dominant power to subvert. Openness stands as a quality which will always attract any power to implement appropriation in it by establishing order and eventually make it physical. The World to Come is located in Chaim's mother's "square and enormous lap". By lying on his mother's lap, he has turned into a baby. What is more interesting is the condition following his bodily transformation.

My history falls away, like sacks of grain from a careless famer's wagon. I begin to forget everything. Names of trees ... times of day ... the words of the morning prayer ... the Bund ... details of leases, of mortgages ... the purpose and function of cravats, of wine, of air ... all remove themselves, one by one, from my understanding. Beneath this large woman's caressing hands, I forget my children's names. Even their faces leave me. I no longer recall how I earned my living or why I died. I'm floating, free from detail, although I find I can still, without difficulty, remember my name (p. 256). 
The portrayal of a mother's lap is a metaphor for the early stage of life when there are no political and social interests. What exists within the lap is the intimate stage between mother and child. This is the same concept of the intimate suggested by Hannah Arendt, a space that is not covered by either the rules of the public or domestic sphere (Degabriele, 2010). In this space, classifications have not existed yet. Any differentiation is unknown, including the ability of the baby to differentiate between himself and the mother. This is known as a period prior to Lacan's mirror stage when the infant does not recognize himself as a being. Sadler (2006) states that the mirror stage is a period when an infant is performing identification, coming to know objects, and perceiving that some images bear greater importance than others. The simplest form of early classification thus happens in the stage. What then exists before the mirror stage is space free from any classifications. Since there is no perception of subject and object, hegemony also does not exist. There is no one to be subverted and no one to dominate. This free space is also what Foucault refers as heterotopia, a space of otherness and difference (Foucault cited in Gonçalves, 2018). Gonçalves elaborates it as the space that is located outside hegemony, where there is no power being contested and thus no resistance is produced.

In the narration's version of the World to Come, all memories are detached from Chaim. He slowly forgets common knowledge, daily activities, people he knows, how he dies, and finally his own name. This process shows how Chaim performs his final resistance by moving from everything he knows, receives, and achieves during his lifetime to liberation. This includes detachment from his identity for he completely forgets his name as the final stage of the disengagement process. A name is one distinguishing feature from Jewish identity that is often used as a reason to persecute them. There are many cases when the survivors change their names once they arrive in America. It is argued as one of the efforts to detach themselves with their past. When Skibell chooses to name his protagonist as Chaim Skibelski, the resemblance shows that Skibell's name is derived from his great grandfather. The name has gone through an appropriation process.

What differentiates Chaim's detachment in the narrative and most of the Jews in real life is that Chaim is successfully liberated. This liberation is only possible to perform if someone has been able to dissociate themselves completely from their identity. It also symbolizes the state when somebody finally can let go of the trauma that haunts. However, it is impossible to do by those who are still alive. Skibell perfectly describes the longing of the survivors and their descendants to be in a state of liberation, yet the state is only possible to achieve when they die. It is also an impossible task for them to completely dissociate themselves from the trauma as the trauma has become an inseparable part of their identity. The struggle to deal with the trauma thus is a lifetime struggle that they have to endure.

\section{CONCLUSION}

The main character in Joseph Skibell's Holocaust novel A Blessing on the Moon is building resistance through spatial movement strategy. The strategy is supported by the magical realist style of the narration that employs journey as a thematic device that makes the character possible to visit several spatial 
Sumaryani, S. (2021). Spatial movement as a resistance strategy in a holocaust novel A Blessing on the Moon. EduLite: Journal of English Education, Literature, and Culture, 6 (1), 165-178.

http://dx.doi.org/10.30659/e.6.1.165-178

locations with various scales and characteristics. What unites these locations and gives reasons for the protagonist to perform constant detachments from them is the order and border imposed by some omnipresent power within the locations' structure. This structure has turned the initially diverse space into the rigid place whose condition has been appropriated to meet the hegemonic interests.

Several distinct features found within the spatial locations that have been appropriated by the hegemony can be indicated by the visible borders and orders. The new structure is used by the hegemonic power to draw classifications and divisions which eventually make them easier to carry out a surveillance system. This political concept of space in the narrative is used to explain the trauma that haunts the survivors of the Holocaust and their descendants. The trauma has turned into memory that keeps penetrating their private space to the extent that it has also shaped their identity. In the modern time, there is no talk about Jewishness that does not involve the Shoah.

The geographical migration as a response to the hegemony is a strategic resistance by the protagonist to achieve his aim: finding the World to Come. The spatial movement also symbolizes the migration of the European Jews to several places, mainly the United States of America and Israel, due to the atrocities committed in the Holocaust. The location of the World to Come in the novel is described as a bodily-scale space located in the protagonist's mother's lap. The protagonist's success to reach this spatial location is followed by the transformation of the protagonist's body into a baby. This body shall not be perceived as a physical body, instead a magical body that depicts space without classifications. This type of space functions as a liberating space for when there are no classifications, identity perishes, which eventually provides a perfect spatial location for the protagonist to free himself from the persecution.

For the Jewish people, dissociation from their identity is an impossible task to do. Skibell's narration thus implies how the Jewish survivors and descendants should embrace their identity that has been intertwined with the Holocaust. This acceptance should be applied as well to the way they deal with the trauma. Like what Skibell has done, instead of rejecting it, he embraces it by creating a magical journey that enables him to put meanings through his protagonist's resistance on spatial locations that fetter him and searching of the spatial location that liberates him.

\section{REFERENCES}

Arva, E. (2008). Writing trauma: The Holocaust in magical realist fiction. Beyond Philology: International Journal on Linguistics and Literary Studies University of Gdansk, Poland, 5, 75-104.

Barel, E., Sagi-Schwartz, A., Van Ijzendoorn, M. H., \& Bakermans-Kranenburg, M. J. (2010). Surviving the Holocaust: A meta-analysis of the long-term sequelae of a genocide. Pyschological Bulletin, $136 \quad$ (5), 677-697. https://doi.org/10.1037/a0020339.

Dean, S. C. (2012). Intergenerational narratives: American responses to the Holocaust. Doctoral thesis. The United States of America. 
Edulite Journal of English Education, Literature, and Culture Vol. 6, No. 1, February 2021, pp. 165-178

E-ISSN: 2528-4479, P-ISSN: 2477-5304

http://jurnal.unissula.ac.id/index.php/edulite DOI: http://dx.doi.org/10.30659/e.6.1.165-178

https://repository.asu.edu/attachments/93631/content//tmp/package4Ns5AF/Dean_asu_0010E_11671.pdf

Degabriele, P. (2010). Intimacy, survival, and resistance: Daniel Defoe's A Journal. English Literary History Johns Hopkins University Press, 77 (1), 1-23. https://doi.org/10.1353/elh.0.0080.

Derrida, J. (1997). Of grammatology. The John Hopkins University Press.

Faris, W. B. (2004). Ordinary enchantments: Magical realism and the remystification of narrative. Vanderbilt University Press. https://muse.jhu.edu/book/380.

Foucault, M. (1979). Discipline and punish. Penguin.

Foucault, M. (1990). The history of sexuality, vol 1: An introduction. Vintage Books.

Gonçalves, A. F. G., (2018). Spaces of resistance: Heterotopia and dystopia in Toni Morrison's Home. Via Panoramica: Revista de Estudos Anglo-Americanos, 7 (3), 93-102. http://193.137.34.194/index.php/VP/article/view/4524.

Grimwood, M. (2007). Holocaust literature of the second generation. Palgrave Macmillan.

Harvey, J. H. (2002). Perspectives on Loss and Trauma. Sage Publishing.

Kolár, S. (2017). Magical realism and allegory in Joseph Skibell's A Blessing on the Moon. Brno Studies in English, 43 (2), 95-110. https://doi:10.3390/genealogy3040051.

Koláŕ, S. (2019). Everybody's Holocaust? Tova Reich's satirical approach to Shoah Business and the Cult of Victimhood. Genealogy, 3 (4), 1-11. https://doi.org/10.3390/genealogy3040051.

Mishor, Z. (2016). Digging the well deep: The Jewish "Ultra-Orthodox" Relationship with the Divine Explored through the Lifeworld of Breslov Chasidic Community in Safed. (Doctoral Thesis, The University of Sydney, Sydney, Australia). https://ses.library.usyd.edu.au/bitstream/handle/2123/15928/mishor_z_thesi s.pdf? sequence $=5 \&$ is Allowed $=y$.

Romero, J. S., \& Rodríguez, L. M. L. (2006). Gendered spaces and female resistance: Virginia Woolf's "The Mark on the Wall". Miscelánea: A Journal of English and American Studies, 34, 93-108. https://dialnet.unirioja.es/descarga/articulo/2366419.pdf.

Sadler, G. B. (2006). Situating Lacan's Mirror Stage in the Symbolic Order. Journal of Philosophy: A Cross-Disciplinary Inquiry, 2 (5), 10-18. https://doi.org/10.5840/iphilnepal2006259.

Saperstein, J. (1984). A craving for history: Immigrant themes in Jewish-American Literature. (Doctoral Dissertation, University of New Hampshire, New Hampshire, The United States of America). https: / / scholars.unh.edu/cgi/viewcontent.cgi?article=2434\&context=dissertatio n.

Shabanirad, E., \& Dadkhah, M. (2017). A Foucauldian study of space and power in two novels by Nadine Gordimer. Gema Online Journal of Language Studies, 17 (4), 113-127. http://doi.org/10.17576/gema-2017-1704-08.

Skibell, J. (2010). A blessing on the Moon. Algonquin.

Tyler, J. (2004). Self and space, resistance and discipline: A Foucauldian reading of George Orwell's 1984. Social \& Cultural Geography, 05 (1), 129-149. https://doi.org/10.1080/1464936032000137966. 
Sumaryani, S. (2021). Spatial movement as a resistance strategy in a holocaust novel A Blessing on the Moon. EduLite: Journal of English Education, Literature, and Culture, 6 (1), 165-178.

http://dx.doi.org/10.30659/e.6.1.165-178

Upstone, S. (2009). Spatial politics in the postcolonial novels. Ashgate Publishing.

Conflict of Interest Statement: The authors declare that the research was conducted in the absence of any commercial or financial relationships that could be construed as a potential conflict of interest.

Copyright (0) 2021 Sumaryani. This is an open-access article distributed under the terms of the Creative Commons Attribution License (CC BY). The use, distribution or reproduction in other forums is permitted, provided the original author(s) and the copyright owner(s) are credited and that the original publication in this journal is cited, in accordance with accepted academic practice. No use, distribution or reproduction is permitted which does not comply with these terms. 